\title{
MANAGEMENT OF CULTURE SHOCK
}

MAREK KOCAK

The rise of globalisation has led to many changes in the nature of how businesses operate including an increasing number of long-term international assignments, which remains for many organisations a challenging problem to the present day. The aim of this paper is, therefore, to provide readers with the general overview of the existing research and findings regarding the topic of cross-cultural adjustment of the expatriates leaving for a foreign assignment and their suitable management procedure in regards to the most effective ways of how different aspects of cross-cultural adjustment could be increased, and thus success of the expatriates in the foreign assignment maximised. 
The nature of today's business environment is becoming more globalised and interconnected on the international level than ever before (Giddens, 1999; Friedman, 2005; Inkpen and Ramaswamy, 2006). On one hand, this globalised business environment provides organisations with unparalleled opportunities, whereas on the other hand, it also offers tremendous challenges due to a higher level of complexity, which results from conditions of multiplicity, ambiguity, and interdependence (Lane, Maznevski, and Mendenhall, 2004). Within many organisations, there can be seen increased multiculturalism and thus increased interaction between employees of different cultures. The culture in the context of this discussion could be defined as follows:

Culture is an integrated system of learned behaviour patterns that are characteristic of the members of any given society. Culture refers to the total way of life of particular groups of people. It includes everything that a group of people thinks, says, does, and makes - its systems of attitudes and feelings. Culture is learned and transmitted from generation to generation (Kohls, 1996, p. 23).

To put it briefly, culture could be understood as a shared meaning system (Fisher, 2009). It implies that the environment, which is more prone towards increased interaction between employees of different cultures, is more open to, and in some cases, directly requires an increasing number of short-term business trips to foreign countries or even long-term foreign assignments. These international assignments are, however, very beneficial both for expatriates as well as for the organisations. According to the research done by Oddou and Mendenhall (1991), foreign assignments increase expatriates global perspectives, increase the ability to communicate more effectively with people from culturally diverse backgrounds, or better comprehend business trends.

Benefits for the organisation that are arising from international assignments may include intersubsidiary communication and coordination (Boyacigiller, 1991; and Rosenzweig, 1994) due to the corporate philosophies and vision, which are likely to be transferred together with the expatriate. Similarly, Boyacigiller (1991) argues that the use of expatriates can help the organisation to form links with host-country governments, local businesses, or other interest groups. This form of connection is likely to provide the organisation with a competitive advantage over competition, especially when the organisation is the first one among competitors to make this form of connection, and thus likely to gain the 'first mover advantage'. For these reasons, it could be argued that the success of an expatriate in a foreign assignment increases an organisation's overall efficiency as well as profitability.

\section{The success of international assignments is, nevertheless, to a large extent affected both by the native culture of an expatriate and the culture to which an expatriate is assigned.}

However, due to the effect of globalisation, which increases the interconnectedness and interaction of different cultures, and thus seems to converge behaviour among countries, one might mistakenly come to the conclusion that the effect of the difference of cultures is insignificant for an expatriate and thus negligible. This kind of reasoning is, however, flawed and Schneider and Barsoux (2002) argue that cultural differences are not disappearing in the process of globalisation, instead the problem may be in the inability to recognise the presence and the force of the culture. Similarly, the survey of 12,000 world managers done by Harvard Business Review indicates that "the idea of a corporate global village where a common culture of management unifies the practice of business around the world is more dream than reality" (Kanter, 1991). 
Thus, not only are there different national cultures in different countries that need to be taken into consideration as they play a role in the success of an expatriate, but also different styles of management need to be taken into account and applied to fit the specific organisational culture which is always to some extent influenced by employees' national cultures. Similarly, the factors of the individual expatriates that are likely to have an effect on the success of an assignment needs to be thoroughly evaluated. For these reasons, there exists cross-cultural management, which could be understood as follows:

Cross-cultural management is the study of the behavior of people in organizations located in cultures and nations around the world. It focuses on the description of organizational behavior within countries and cultures, on the comparison of organizational behavior across countries and cultures, and, perhaps most importantly, on the interaction of peoples from different countries working within the same organization or within the same environment (Adler, 1983, p. 226).

However, the existing research indicates relatively large differences between the existing practices (or lack of practices) of cross-cultural management by organisations and what is generally agreed to be the most successful set of practices that maximise the success of an expatriate in a foreign assignment. The cost of largely ignoring and not implementing such practices is certainly not negligible. Various studies have found that between sixteen and forty percent of all expatriate managers who are given foreign assignments end these assignments early due to their poor performance or their inability to adjust to the foreign environment (Black, 1988; Dunbar and Ehrlich, 1986) and as much as fifty percent of those who do not return early function at a low level of effectiveness (Copeland and Griggs, 1985). Black and Gregersen (1991, pp. 462-463) further argue that "the cost of ineffective expatriates may well be higher than the costs of 'failed' expatriates". Failure, therefore, could be also considered to include factors such as stresses, strains, and underperformance of the expatriate, negative outcomes of repatriation, negative effects on the expatriate's family, the career prospects of expatriate's partner, or negative view about the prospect of overseas postings in the future (Harzing, 1995).

Therefore, once the appropriate practices are implemented, the failure rate as well as the ineffectiveness of the expatriates who are having difficulties with adjustment could be lowered and thus related costs of such failure or low efficiency reduced. The following overview is thus a summary of the most important theory necessary for understanding cross-cultural adjustment, and the practices the existing research found effective in the maximisation of the success and effectiveness of foreign assignments.

\section{CULTURE SHOCK}

When an expatriate is entering a new environment, there is always a certain degree of uncertainty about what behavior is acceptable. According to Oberg (1960), such uncertainty is due to the loss of all familiar signs and symbols of social intercourse (both in the work and non-work environment), most of which are not carried out on the level of conscious awareness. The reason for not consciously carrying these cultural signs and symbols, and thus not realising the loss of these culturally inherited habits, stems from the fact that culture has a major role to play in the way an individual's psychology is shaped due to human ethnocentric nature (Berry, et al., 1997). In other words, it is not only cultural differences as such that contribute to the culture shock, but also each individual's psychology which is by default predetermined by our own culture to unwittingly see and judge the outside world through the lenses of our own culture. Because particular beliefs, perceptions, thoughts, and feelings (broadly called basic underlying assumptions) operate at an unconscious level (Thomas, 2008); some degree of culture shock is, therefore, always inevitable. To get a better notion of this complex idea, the core of the problem could be pointedly illustrated in a quote by Eagleton (2000), "one's own way of life is simply human; it is other people who are ethnic, idiosyncratic, culturally peculiar." 
This implies that even though an expatriate takes proactive measures both in the form of studying the new environment in advance as well as in trying to perceive new environment non-judgmentally, the individual will always face stress, uncertainty, and the differences of behavioural expectations, both due to imperfect knowledge of the novel culture as well as an unawareness of their unconscious cultural programming, resulting in some degree of culture shock.

The physical, psychological, and behavioural reactions caused by culture shock occurs when expatriate's "cultural clues, the signs and symbols which guide social interaction, are stripped away" (Piet-Pelon and Hornby, 1992, p. 2), and thus "the expatriate is not (fully) able to understand any type of feedback from the novel environment due to the lack of (complete) knowledge of a novel culture" (Louis, 1980). The symptoms of culture shock can include homesickness, increased irritability, the feeling of helplessness, exaggerated concern over drinking water, food, and bedding, or excessive criticism of local customs or ways of doing things (Oberg, 1960). The cross-cultural adjustment could be then understood and measured as the degree of psychological comfort with different aspects of a new country (Black, 1988; Nicholson, 1984).

Oberg (1960) postulated that a degree of psychological comfort with a host country could be divided on four phases: honeymoon, crisis (sometimes called also shock), recovery, and adjustment. Based on these four phases the degree of adjustment could be assessed. The first phase may last from a few days up to six months depending on the circumstances. But generally researchers agree that the honeymoon phase is relatively short (Gullahorn and Gullahorn, 1963; Harris 1979; Moran, 1989; and Torbiorn, 1982). During this stage an individual is fascinated by the new environment (Adler, 1986). The second phase crisis - starts when an expatriate starts to cope with the real conditions of the foreign environment. Due to the difficulty of an individual adjusting to the foreign environment, one reacts as being hostile or even aggressive towards the foreign environment. This negative attitude is then further exacerbated by the indifference of host nationals towards the difficulties of the expatriate due to the lack of understanding of the expatriate's problem(s). It is usually at this stage when the success of an expatriate is decided. Oberg (1960) argues that when an expatriate is able to overcome this stage, he/she is able to stay in the new environment. Conversely, however, when an expatriate is unable to overcome this stage, he/she leaves the country before he/she reaches the nervous breakdown. This "breaking point" is on the cross-cultural adjustment timeline more clearly specified by Black (1988) who argues that the culture shock as such appears specifically between the second and the third stage "when the person has received the maximum amount of negative feedback but as yet has very little idea as to what the appropriate behaviors are". In the third phase an expatriate begins to be open to the new cultural environment although he/she can still experience some difficulties. Lastly, in the fourth stage an expatriate completely accepts the foreign country and its customs as another way of living and begins to enjoy them.

\section{CURVES OF ADJUSTMENT}

Various adaptation development models have attempted to describe degrees of the different stages of cross-cultural adjustment. The most prominent from them are the "U-curve" by Lysgaard (1955) and "Wcurve" by Gullahorn and Gullahron (1963). U-curve describes the four phases of cross-cultural adjustment as postulated by Oberg, whereas $\mathrm{W}$-curve diverges from $\mathrm{U}$-curve after the stage of culture shock, which is followed only by initial adjustment from which the degree of adjustment is again decreased due to mental isolation, which then definitely succeeds in a high level of adjustment due to the expatriate's acceptance and integration into the new environment. For a better picture of the variances between the two curves, the graphical depiction of the two curves could be seen on p. 67. 


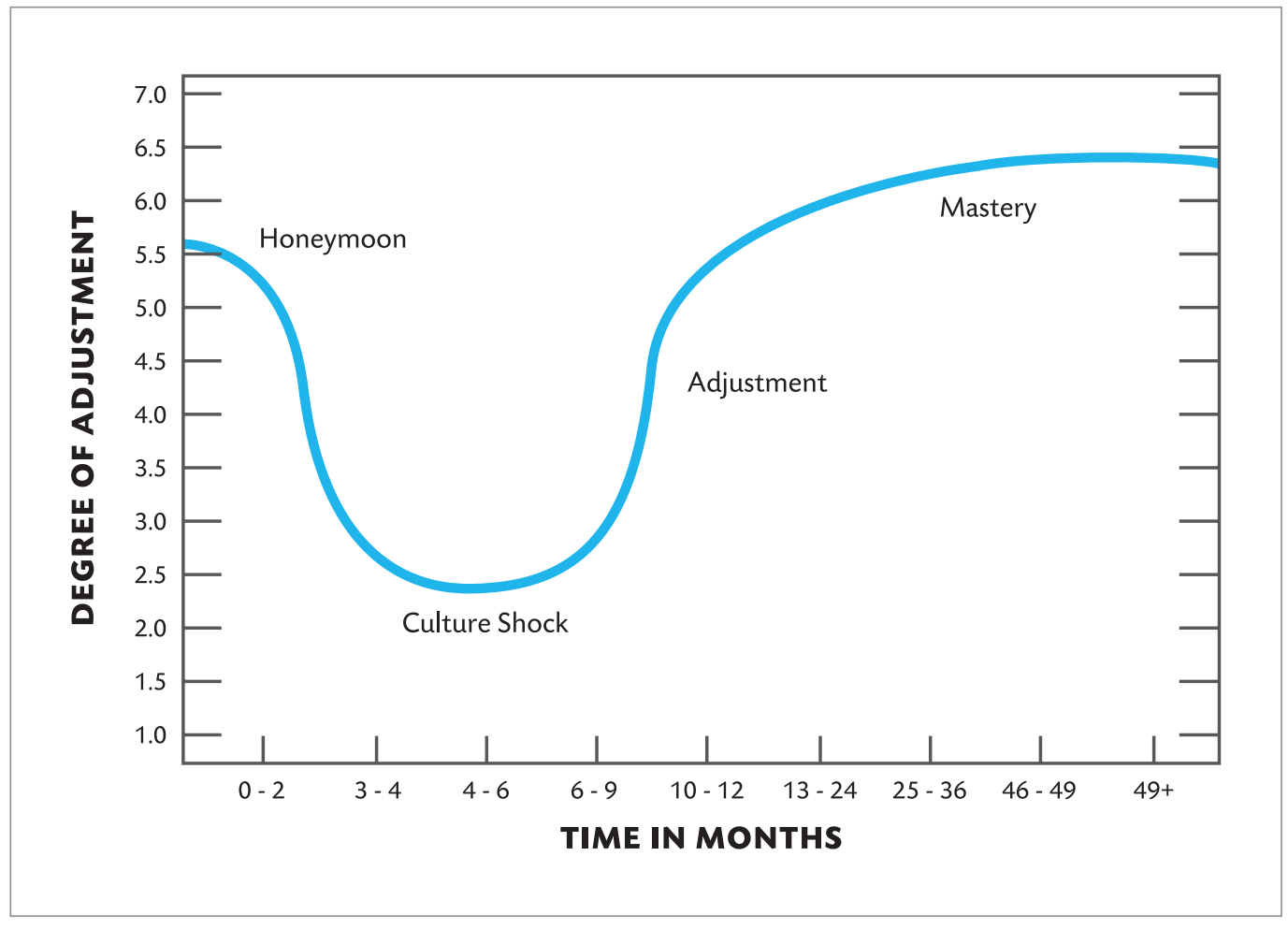

Figure 1: U-curve model by Lysgaard

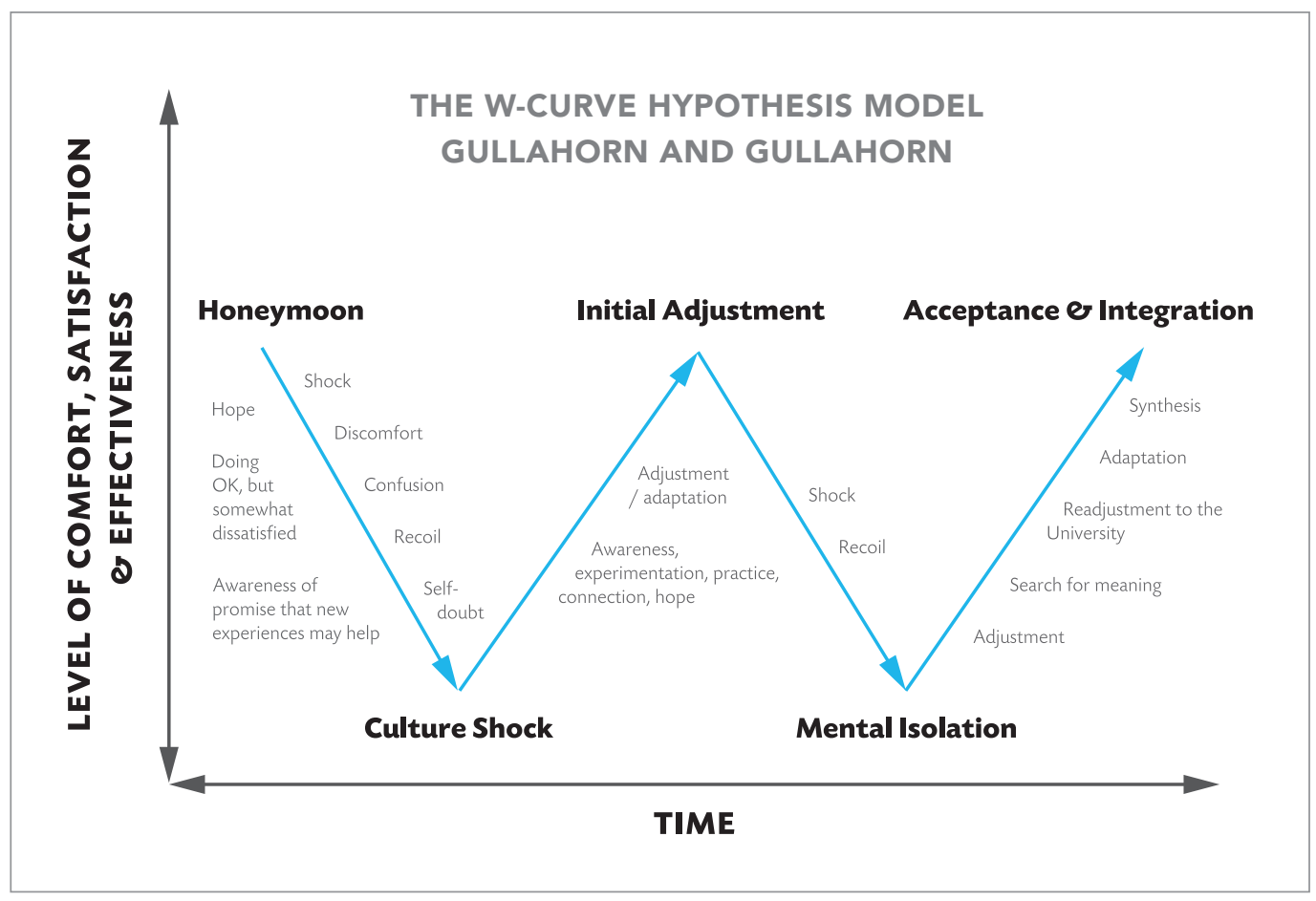

Figure 2: W-curve model by Gullahorn and Gullahorn 
However, although according to Dutton (2011) the existing research indicates that different stages of cross-cultural adjustment are the real phenomenon, broadly empirically accurate, Churn (1982) argues that the research support for the U-curve model is inconclusive. In addition, Ward et al. (2001) and Ward et al. (1998, p. 290) went as far as rejecting the U-curve model of sojourner adjustment completely. Similarly, Bernando (2006) and La Brack (2013) recommended, based on an exhaustive review on the validity of the 'curves', to stop using the models, as they have not withstood critical empirical testing and research. The rejection of adjustment curves could be based on the grounds of findings such as of Churn (1982) and Stening (1979), which indicate that the level of anxiety and the length of experienced anxiety are likely to differ for individual expatriates. In addition, different patterns of adjustment have been also found between work and non-work environment of expatriates, as well as between expatriates and their spouses (Briody and Chrisman, 1991; Nicholson and Imaizumi, 1993).

These different patterns of adjustment between expatriates as well as their spouses could be explained by the differences between various factors such as the ability to speak language, individual factors, foreign work experience(s), expectations and requirements, demographic factors, the differences between job and organisational factors (e.g. job level, cross-cultural training or lack thereof), and due to the differences between environmental factors (e.g. cultural novelty, social support).

Importantly, although it might seem intuitively appealing, it should not be deduced from the curves that the lower the amplitude of the curve the better the performance of an expatriate. The research done by Thomas and Lazarova (2006) actually indicates the contrary. Specifically that the highest-performing expatriates usually experience the most severe culture shock and thus have the most difficult adjustment process. Likewise, steep amplitude of the curve (or in other words the severe shock) should not be understood as an indicator of high-performance in an expatriate as the steep curve is not a reason itself for high performance, but merely a consequence of desirable attributes that enable expatriates to be effective in a new environment (such as perceptual skills or others' orientation) which have a simultaneously negative effect on the culture shock. Therefore, it could be argued that organisations should proactively help to decrease an expatriate's culture shock, but not infer an expatriate's unsuitability for the foreign position from the high aptitude of the cross-cultural curve.

Thus because the curve would differ in each individual, it implies that for ensuring the possibly the smoothest cultural transition of an expatriate the different aspects and stages of cross-cultural adjustment should ideally be closely analysed as there might occur specific problems that would diverge from the specific curve of adjustment. By doing so, identified problems can be proactively tackled in advance. Thus the psychological discomfort of an expatriate could be further reduced and their chances in succeeding in the foreign assignment would be maximised. Failing to recognise these nuances or more significant differences in behaviour between each expatriate would mean for an organisation to diverge from an optimal crosscultural management strategy and thus decrease in its efficiency.

\section{DIFFERENT ASPECTS OF CROSS-CULTURAL ADJUSTMENT}

As already mentioned, the reduction of culture shock can be seen as the process of cross-cultural adjustment (Black, 1988; Black and Gregersen, 1991; and Churn, 1982) where the cross-cultural adjustment could be understood as the degree of psychological comfort with different aspects of a host country (Black, 1988; Black et al., 1991; Oberg, 1960; and Nicholson, 1984). Aspects to which the degree of psychological comfort could be related, however, among many researchers differ. Although it was thought in the past that cross-cultural adjustment is one-dimensional phenomenon (Gullahorn and Gullahorn, 1962; Oberg, 1960; and Torbiorn, 1982) where the degree of adjustment could be measured 
by job satisfaction (Abe and Wiseman, 1983; Hammer, Gudykunst and Wiseman, 1978; and Torbiorn, 1982), life satisfaction (Cui and Van den Berg, 1991), ratings of depression (Armes and Ward, 1989), or organisational commitment (Wanous and Lawler, 1972; and Reichers, 1985). More recent research indicates that cross-cultural adjustment could be also understood as a multidimensional phenomenon (Black, 1988; Black and Stephens, 1989).

According to this research, cross-cultural adjustment could be divided on three main dimensions or sometimes referred as facets. The first facet is connected to work adjustment. This facet includes adaptation to job roles and task as well as to novel work environment. The psychological uncertainty resulting from this facet of adjustment can be effectively reduced by similarities in various types of policies, task requirements, and procedures between the parent company and host subsidiary to which the expatriate was assigned (Black et al., 1999). The second facet is called interaction adjustment and relates to the level of comfort arising from the interaction with host nationals including both work and non-work environments. The third facet is then called general adjustment and according to Black (1988), refers to general adaptation to living in the particular novel culture. According to Black and Stephens (1989), this facet includes various factors level of health care, cost of living, or housing conditions.

Generally it could be said that a degree of psychological comfort could be enhanced by learning about appropriate, less appropriate, and inappropriate types of behaviour. Factors that generally facilitate crosscultural adjustment could be seen as those that reduce the degree of an expatriate's psychological discomfort, whereas factors that increase the degree of an expatriate's psychological discomfort reduce the ability to adjust (Black, 1988; Brett, 1980; and Church, 1982).

However, from the point of view of cross-cultural adjustment as being a multifaceted phenomenon, it could be argued that it is important to take into account different facets of an expatriate's adjustment and enhance an expatriate's appropriate types of behaviour in each specific facet of adjustment in order to maximise the overall reduction of an expatriate's level of psychological discomfort. This argument is supported by the findings of Black (1988) who found that specific facets are very strongly related to the general adjustment of an expatriate.

In line with this logic, it could be argued that because the curves of adjustment unite different facets of adjustment into one unifying curve; such a curve would be of very little help when trying to facilitate an expatriate's adjustment by identifying root cause(s) of expatriate difficulties in each facet of adjustment as such information would not be obtainable from the curve. In other words, whereas the aptitude of the curve would provide information about the expatriate's time and severity of the difficulty with adjustment, the curve would fall short in providing information about the extent to which these difficulties can be attributed to each facet of adjustment. Arguably then, more an effective alternative could be to use specific curve for the description of each facet of adjustment. By doing so, the problem(s) in each particular facet would be more transparent, and thus proactive measures to reduce or completely eliminate such problems could be more accurately and effectively applied.

The reduction of expatriate's difficulties with adjusting relating to each specific facet of adjustment could be done while being in the country and going through culture shock and different stages of cross-cultural adjustment, which could be generally called in-country adjustment, and prior to entering the country called anticipatory adjustment. The theory seems to agree that organisations can proactively accelerate the process of cross-cultural adjustment of expatriates by implementing suitable selection mechanisms and criteria (Black, 1988; Thomas, 1998), applying appropriate cross-cultural training (Worchel and Mitchell, 1972), and using suitable organisational (Stroh et al., 1994; Torbiorn, 1982) and job factors (Nicholson, 1984; Thomas, 1998; Tung, 1981). 


\section{SELECTION MECHANISM AND CRITERIA}

The failure rate of expatriates is extraordinarily high even despite the fact that it is generally the more successful domestic employees who are sent abroad (Tung, 1981). This rate of failure is primarily due to the fact that often the same selection mechanisms and criteria are used for selecting both expatriates as well as domestic employees with the identical or similar title. The primary decision criterion used by firms in selecting employees for foreign assignments used to be technical competence (Bormann, 1986; Hays, 1971; Howard, 1974; Ivancevich, 1969; Miller, 1975; Tung, 1981). Surprisingly, however, more recent research indicates that very little has changed as technical competence and managerial performance in the domestic setting still lead the list of selection criteria and other criteria that could play a significant role in the expatriate's performance and overall success in the foreign assignment, are still generally neglected (Anderson, 2005; Graf, 2004; Tye and Chen, 2005). However, the idea of not distinguishing between selection practices of domestic employees and expatriates, by relying mainly on technical expertise and managerial competence for both cases, is arguably not very well-founded as requirements for the performance for expatriates and domestic employees are likely to differ (Lee, 2005) as well as factors affecting their success.

Firstly, domestic employees and foreign expatriate have different expectations and requirements about the job position that organisations should during the selection process take into consideration. According to Stahl, Miller, and Tung (2002) unlike with domestic employees, a significant factor in the expatriate's decision to accept an overseas assignment is the enhancement of an international career, especially then, when it comes to an expatriate's first posting. Similarly, Tharenou (2003) agrees that individuals with high outcome expectancies, but interestingly also with few family concerns such as the employment of the spouse or children's schooling, would be more receptive to a foreign assignment. Not recognising these expectations and requirements can lead to decreased satisfaction of an expatriate and thus increased probability of failure.

Secondly, when selecting potential candidates for a foreign assignments, an organisation needs to be aware of the effect of novel environment on an expatriate. The main difference in the work environment is that it will generally consist of more host nationals rather than compatriot expatriates. Therefore, the organisational culture of the expatriate will more reflect a host culture than the expatriate's domestic culture (Louis, 1980) and an expatriate will have to adapt to such behaviours, norms, and values. It is important to note, however, that not all the expatriates will experience the same level and length of anxiety during the crosscultural adjustment (Churn, 1982; Stening, 1979). Some expatriates may return home early, some may not achieve the mastery stage in the new environment, whereas others may complete the foreign assignment without really adjusting (Thomas, 2008). Therefore, organisations during the selection process should ideally also concentrate on selecting candidates with specific abilities and skills that will decrease and shorten the experienced level of anxiety with the new culture and thus maximise the probability of the success in the foreign assignment.

These individual factors can be according to Mendenhall and Oddou (1985) divided on self-efficacy, relational skills, and perceptual skills. The first set of skills called self-efficacy or in other words self-oriented skills are according to Mendenhall and Oddou (1985) and Bandura (1977) important as an expatriate possessing this skill has an ability to believe in oneself and one's ability to succeed in novel environment, despite this new environment being for an expatriate very uncertain (Black et al., 1991). Therefore, possession of this skill leads to learning new behaviors that better correspond to the expectations of the expatriate. This in turn will decrease the level of uncertainty of the expatriate and thus facilitate a degree of adjustment. The second set of skills called relational skills are important for the expatriate in order to provide information about what is expected from him in the novel environment. According to Mendenhall and Oddou (1985), the greater level of relational skills an expatriate possesses, the easier it is for him/her to communicate with host nationals. Logically, the more an expatriate communicates with host nationals, the more 
information about types of appropriate behaviours in the novel environment he/she receives (Black et al., 1991), and thus can adapt accordingly. This is because information received from this communication reduces the uncertainty associated with the new environment. In fact, there could be found a positive relationship between time spent with host nationals and the degree of general cross-cultural adjustment (Black et al., 1991). The third set of skills that falls into category of individual factors are perceptual skills. These skills help the expatriate to better understand and separate appropriate behaviours in the host country from less appropriate or inappropriate ones (Black et al., 1991). It implies that by having a high degree of perceptual skills, an expatriate can decrease the uncertainty connected to a novel environment.

To summarise individual factors, it could be said that candidates with a higher ability to manage psychological stress, communicate effectively, and a higher ability to establish personal relationships were more likely to succeed in the foreign assignment. In addition to the consideration of expatriates' expectations and requirements and individual factors, there are also other relevant factors that need to be taken into consideration during the selection process in order to maximise the success of an expatriate, such as previous foreign work experience, ability to speak a foreign language, and demographic factors.

Previous foreign work experience was also found to be an important uncertainty reduction mechanism (Dawis and Lofquist, 1984; Nicholson, 1984; Torbiorn, 1982). Interestingly, however, according to Black (1988), an expatriate's previous foreign work experience is only positively related to work adjustment for expatriates, but not to general adjustment. This finding could be, however, considered to be in a disagreement with the findings of Dunbar (1992) which found that expatriates with previous work experience are more likely to use appropriate intercultural behaviours (which are arguably also helpful in facilitating general adjustment). Torbiorn (1982) also found that the length of previous foreign work experience seems to have no effect on current foreign adjustment, whereas other studies indicated that the amount of previous foreign experience is positively related to adjustment as well as to job satisfaction (Naumann, 1993; Parker and McEvoy, 1993; Taukechi and Hannon, 1996). The research of Black and Gregersen (1990) even argues that previous foreign experience can be negatively related to particular attitudes of expatriates, such as the amount of discretion that expatriates feel they have in performing their jobs.

Therefore, the existing research suggests that the intuitively appealing notion that previous foreign experience is straightforwardly positively related to all facets of adjustment as well as to the success of all expatriates equally is perhaps an oversimplification. Based on the findings, it could be argued that similarly as there are differences between expatriates in experienced degrees and lengths of adjustment to the new environment, there could be also found differences between expatriates in benefits that previous foreign work experience(s) has given to them, either due to different abilities of expatriates to learn and benefit from the experience or due to the differences in the characters and lengths of foreign work experience between each individual candidate.

Another relevant factor for expatriate success is considered by many researchers to be the ability to speak a foreign language. There has been found a positive relationship between foreign language fluency and the degree of interaction with host nationals, and to a smaller extent with adjustment, satisfaction, and commitment (Church, 1982; Thomas and Fitzimmons, 2008). It could be also argued that the ability to speak a foreign language slightly increases an expatriate's performance as there was found a moderate relationship between foreign language fluency and expatriate performance (Mol et al., 2005). The positive effects of the knowledge of a foreign language are often (at least partly) attributed to benefits of so-called social currency (the ability of expatriates to make conversation about everyday things such as weather, local restaurants, or ways of commuting), which can, according to Brein and David (1971), facilitate expatriates' interaction with host nationals. 
However, another explanation could be that the ability to speak is not the primary reason for the expatriate success, but that it could rather be the willingness to communicate that leads to a higher degree of interaction, and the knowledge of the language then merely enables such communication. In such a case, foreign language fluency would be by itself an insufficient factor predicting success unless it was combined with the expatriate's willingness to communicate. This explanation could be supported by several empirical studies that found the ability to a speak foreign language by itself as an ineffective predictor of the success of an expatriate (Benson, 1978). Therefore, it could be concluded that organisations should during selection process not only concentrate on the foreign language fluency, but also on the expatriate's willingness to communicate in a novel environment and the importance of these factors could be assessed in regards to the character of the assignment such as required intercultural interaction.

In order for a selection mechanism to be successful, organisations should also consider demographic characteristics of expatriates such as age, educational level, length of time an expatriate has worked for an employer, or the existence of spouse, or eventually family, as these factors have been found to play both positive and negative roles in the success of a foreign assignment. The following is the summary of the research findings done by Thomas (1998). It was found that age has both positive and negative effects on particular aspects of foreign assignment. On one hand, there was a positive correlation between the age and organisational commitment, job satisfaction, and work adjustment. On the other hand, however, there was found a negative correlation between the age and general satisfaction, willingness to relocate, and intent to leave. Similarly, the length of time a potential expatriate has worked for their employer was found to be positively correlated to job satisfaction, but negatively correlated to intent to leave. The findings also indicate that educational level positively correlates with general adjustment and interaction adjustment, but negatively correlates with job satisfaction, work adjustment, and commitment to the organisation.

Eventually, the selection process should also take into account factors such as the existence of a spouse or eventually family of a potential expatriate that would be leaving with an expatriate as their inability to adjust is the number one reason for the expatriate's inability to succeed in the transition (Hays, 1971; Torbion, 1982; Tung, 1981). The extensive study of expatriates of various nationalities by Arthur and Bennet (1995) indicates that expatriates themselves are also well aware of this issue as they identified family situation as the most important characteristic relating to success in the overseas assignment. On the other hand, however, if an adjustment of a spouse is successful it can increase an expatriate's work performance and job satisfaction (Thomas, 1998).

It could be argued that in order to reduce the spouse's inability to adjust, and thus simultaneously minimise the most likely reason for the expatriate failure, organisations should include in the selection process also factors influencing the spouse's or family's ability to adjust. Therefore, the above described selection criteria should not only apply to an expatriate, but also to their spouse and other members of the family who are entering the new environment with an expatriate. Obviously then the above described criteria should not be applied uniformly to all the members of the family, but rather relevant criteria should be tailored to fit each specific member of the family, such as expectations and requirements about job position would be largely irrelevant for a spouse unless he/she will work in the novel environment, whereas individual factors such as self-efficacy might be even more important to him/her than for an expatriate as he/she will be more likely isolated in the novel environment and thus his/her ability to believe in succeeding in the new, uncertain environment may play a more crucial role in the adjustment than in the adjustment of an expatriate. Once the relevant criteria relating to a spouse or family is thoroughly applied the chosen family members will arguably have better ability to adjust to a new environment than family members of a candidate who are lacking skills that selection criteria found relevant. As a result the spouse's or family's high ability to adjust would be then negatively correlated with the expatriate's intent to leave (Thomas, 1998); therefore, the success of an expatriate will be further increased. 
To summarise selection mechanism and criteria, the existing research indicates that organisations still generally use the same selection mechanisms and criteria (consisting of technical competence and managerial performance) for selecting both expatriates and domestic employees. This goes contrary to the plethora of existing research pointing out other factors that have a significant beneficial effects on the expatriate's performance and overall success in the foreign assignment and which should thus be included in the selection criteria as well. These factors include an expatriate's expectations and requirements, individual factors, previous foreign work experience(s), foreign language fluency, and demographic factors. Furthermore, because the spouse's inability to adjust is the number one reason for the expatriate's failure in the assignment, it is argued that described selection criteria should not be limited only to an expatriate, but should also include spouse and family. In such a case, however, relevant criteria need to be tailored to each specific member of a family, rather than applied uniformly. It is essential that all the above-described factors are not underestimated and are properly considered during the selection process, as they are the first important precondition for the subsequent success of an expatriate. Also, it is necessary to consider these factors at this stage, as they cannot be (e.g. previous foreign work experience), or can hardly be (e.g. foreign language fluency) positively influenced to a significant extent by subsequent cross-cultural training. Although selection mechanism and criteria are limited in its nature, they should be considered as an important acquirement of control of factors that lie beyond the control of cross-cultural training (which is further described below) but, nevertheless, play a significant role in the success of an expatriate.

\section{CROSS-CULTURAL TRAINING}

Similarly, as in the case of selection mechanism and criteria, although the positive effects of cross-cultural training are well known and agreed by different studies (e.g. Beffus, 1988; Black and Mendenhall, 1990; Brislin, MacNab and Nayani, 2008), organisations often fail to provide training whether it be due to insufficient time prior to expatriate departure, or simply due to a lack of belief in the effectiveness of such training (Enderwick and Hodson, 1993; Tung, 1981). Nevertheless, the theory seems to agree that the organisation should not only apply appropriate selection mechanisms and criteria to decrease expatriate failures and inefficiencies, but also proactively accelerate the process of cross-cultural adjustment by understanding and implementing appropriate cross-cultural training as the research supports the conclusion that there is a positive relationship between cross-cultural training and cross-cultural adjustment (Befus, 1988; Early, 1987; Gudykunst et al., 1977; Mitchel et al., 1972; O'Brien, Fiedler and Hewett, 1970; Steinkalk and Taft, 1979; Worchel and Mitchell, 1972). Similarly, there could be found a positive relationship between cross-cultural training and cross-cultural skill development (Black and Mendenhall, 1990) and cross-cultural training and performance (Earley, 1987; Katz, 1977; Lefley 1985, 1986; McDaniel, McDaniel and McDaniel, 1988; Nayar et al., 1968; O'Brien, et al., 1970; Randolph, Landis and Tzeng, 1977; Salisbury, 1971; Worchel and Mitchell, 1972). However, cross-cultural training has an impact on an expatriate's performance only to the extent that that performance has a culturally related component, which nevertheless studies found in most cases (Black and Mendenhall, 1990) as there are mostly expatriates working with other employees of different cultures and within a novel environment. Finally, there is also a positive relationship between cross-cultural training and subsequent success in foreign assignments (Brein and David, 1971; Church, 1982; Mendenhall and Oddou, 1985).

Based on these findings and on meta analysis of Deshpande and Viswesvaran (1992) and of Morris and Robie (2001), it could be concluded that the empirical evidence supports the idea that cross-cultural training has a positive impact on cross-cultural effectiveness. In other words, cross-cultural training limits some risks of an expatriate's failure. This failure, Harzing (1995) argues, could be also considered to include factors such as stresses, strains, and underperformance of the expatriate, or a negative view about the prospect of overseas postings in the future. 
As there is no research indicating otherwise, it could be argued that the research uniformly indicates that cross-cultural training reduces the degree of psychological comfort with different aspects of a host country, or in other words, cross-cultural training positively influences expatriates' cross-cultural adjustment. But although cross-cultural training seems to be in general effective, different aspects of such training need to be understood and taken into consideration, because as it was described more in detail above, cross-cultural adjustment is considered by some to be a multifaceted construct (Black, 1988; Black and Stephens, 1989) with expatriates adjusting to work, to interaction with host nationals, and to general environment (Black and Stephens, 1989). All of these factors determine the extent of success of the expatriate's cross-cultural adjustment and thus his or her success in a foreign assignment.

Surprisingly, however, despite the agreed positive effects of cross-cultural training on the effectiveness on expatriates, there is relatively little known about the effects of different training types (Thomas, 2008). Black and Mendenhall (1989) argue that by drawing on social learning theory for guidance by Bandura (1997), specific training methods should be applied to each specific expatriate based on the difficulty of his or her particular situation (such as degree of cultural novelty, required intercultural interaction, or job novelty). Training methods could be then divided based on the degree of required participation on factual (e.g. books, lectures), analytical (e.g. culture assimilators, classroom language training) and experiential (e.g. field trips, role playing, and interactive language training) from which analytical is the least participative and experimental the most. According to this theory then, the more demanding the situation is for an expatriate, the more participative cross-cultural training should be applied. Applying an experiential method in the most demanding situations seems reasonable, especially in the light of the findings of Brislin et al. (2008) who found experiential training to have the best results.

Similarly, as in the case of the type of training, there is also some uncertainty regarding the appropriate timing of training (Thomas, 2008). Grove and Torsion (1985) argue that in-country training is likely to be more effective after the arrival to the novel environment, when expatriates have a corresponding frame of reference as well as the highest motivations to learn. The existing limited research generally supports the idea of in-country training as being more effective than pre-departure training (Eschebach et al., 2001; Feldman and Bolino, 1999; Selmer, 2001).

However, the existing research indicates that pre-departure training should not be completely disregarded. This is due to the findings indicating that pre-departure training provides an expatriate with accurate information which lead to realistic expectations (Caligiuri et al., 2001; Meglino and DeNisi, 1963), which were consequently found to be positively related to positive outcomes such as to all facets of expatriate adjustment (Black, 1990) and job satisfaction (Feldman and Thompson, 1993; Stroh et al., 1994). Thus pre-departure training is important in a way that it leads to pre-departure knowledge about the host country so an expatriate can reduce the uncertainty of the new environment by anticipating environmental differences (Gullahorn and Bullhorn, 1963).

Although cross-cultural training of the expatriate seems to be effective, such training should not apply only to an individual expatriate, as they often are not isolated individuals without spouses or families (Harvey, 1985). Furthermore, despite the important effect of expatriate's cross-cultural training on cross-cultural adjustment, the failure of an expatriate to living and working in an overseas environment is not the most common reason for the expatriate's inability to succeed in the transition (Tung, 1981). As it was already mentioned above, it is, perhaps paradoxically, the expatriate's family, or spouse's inability to adjust which is the number one reason for the expatriate's inability to succeed in the transition when the expatriate is leaving with the family or spouse (Hays, 1971; Torbion, 1982; Tung, 1981). This is due to the findings of previous research which indicates that "the adjustment of the spouse is highly correlated to the adjustment of the expatriate and the adjustment of the spouse and the expatriate are 


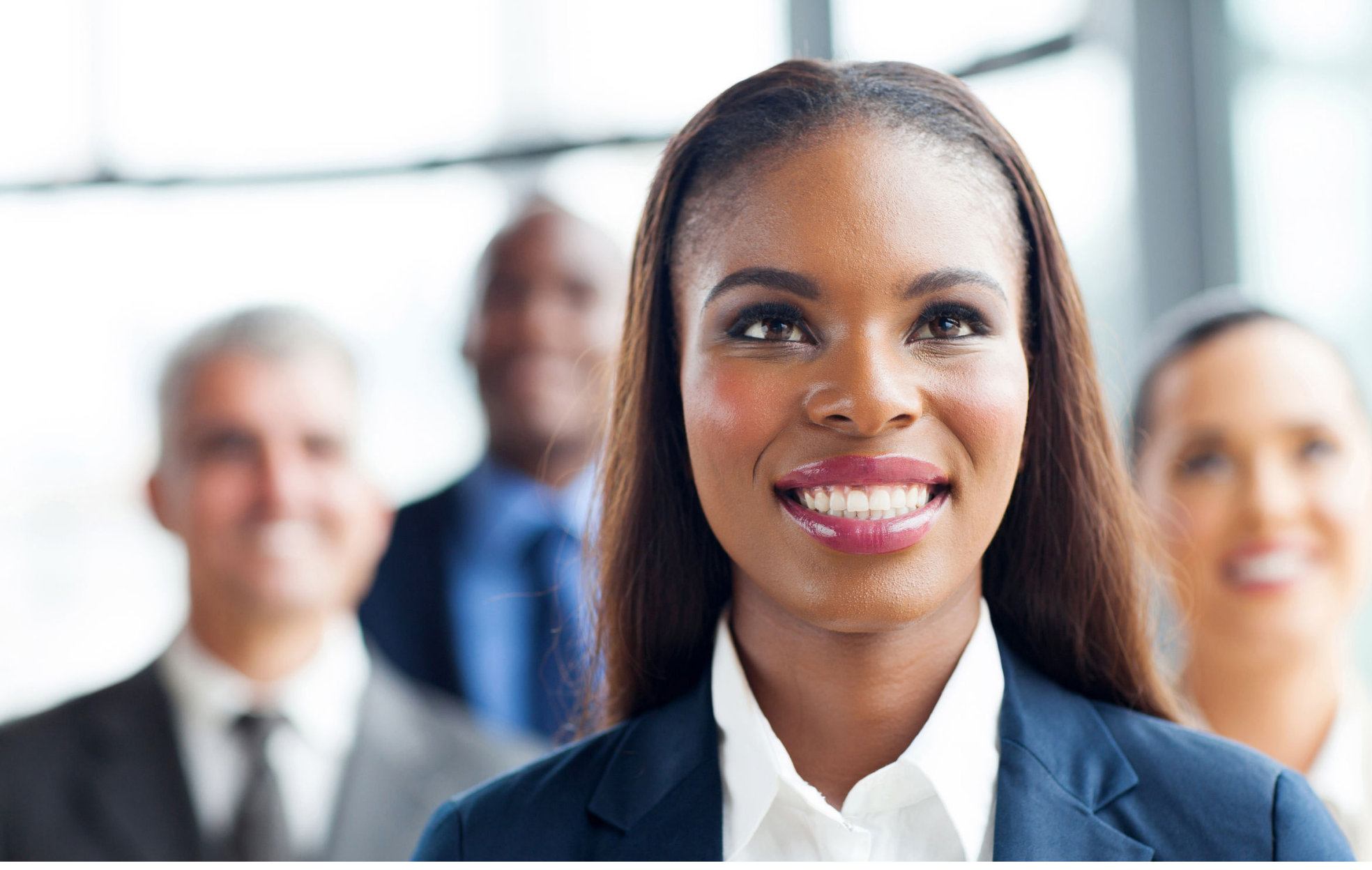

(CHONGQI ZHANG/123RF.COM

positively related to the expatriate's intention to stay in the overseas assignment" (Black, 1989). As there is problem with a spouse's or family's inability to adjust and also there exists evidence suggesting that cross-cultural training facilitates cross-cultural adjustment (Black and Mendenhall, 1990), it could be argued that when an expatriate is leaving for an assignment with a spouse or family, cross cultural training should also include them, as an expatriate's spouse or family's ability to adjust to the changes of new environment has significant impact on the expatriate's transition at work (Black, 1988).

However, if the family's or spouse's adjustment is indeed related to an expatriate's adjustment, it is crucial to understand specific factors accelerating their adjustment and thus adapt cross-cultural training accordingly. Black and Stephens (1989) argue that whereas expatriates adjust to work environment, general environment, and interaction environment, spouses adjust only to interacting with host nationals and to the general foreign environment. Therefore, an expatriate's training should focus on all facets of adjustment, whereas a spouse's or family's cross-cultural training should concentrate only to interaction adjustment and general adjustment.

\section{FACTORS INFL. THE EXPATRIATE AFTER ARRIVAL TO THE NOVEL ENVIRONMENT}

The review so far has only described those ways of how an organisation can reduce an expatriate's psychological discomfort with a host culture that could be implemented prior to entering to a novel environment although they have an effect on an expatriate's in-country adjustment. Firstly, it was discussed that an organisation needs to implement specific selection procedures that will choose from the candidates those expatriates that have specific characteristics that will make them most likely to succeed in the foreign assignment. Secondly, it was explained that these chosen expatriates, with the highest preconditions to succeed, need to undergo cross-cultural training possibly with their families or spouses (though crosscultural training will differ between the expatriate and spouse, or family to concentrate on specific needs). 
However, although the selection process combined with appropriate pre-departure training is important in order to minimise psychological stress arising from a novel environment, Xia (2009) argues that by doing so culture shock will not be completely avoided and moreover the period after entering the novel environment is more crucial for the expatriate when it comes to cross-cultural adjustment as the expatriate needs to transform gained knowledge from cross-cultural training into practice (Cushner, 1994). Therefore, it is reasonable to argue that in-country adjustment should be also carefully considered and planned by organisations when sending its employees on foreign assignments.

Once an expatriate has arrived to the novel country and works in the new environment, there could be various factors that can speed up, slow down, or even completely prevent the expatriate from adjusting to the novel environment, despite previous successful selection process and cross-cultural training which is usually more general in nature and thus have mostly positive effects on non-work factors. Therefore, several other factors (or some aspects of these factors) are important to consider by an organisation once the expatriate arrived to the novel environment as these factors can either further facilitate or inhibit adjustment of an expatriate. Factors with such a potential could be considered to fall in the category of job factors and organisational factors. From the point of view of job factors, there could be found particular job factors that have the potential to facilitate work adjustment. Role clarity is, for example, important for an expatriate as the existing research indicates that it reduces the amount of uncertainty connected to the work situation (Black, 1998; Nicholson, 1984; Pinder and Schroeder, 1987); therefore, it facilitates adjustment at work (Nicholson, 1984). Karasek (1979) and Kahn et al. (1964) argue that role flexibility, another job factor, makes the transition easier as it enables expatriates to make the role more controllable, predictable, and familiar.

Some job related factors were also found to inhibit an expatriate's adjustment. These include role novelty (Burr 1972; George 1980; Minkler and Biller 1979; Pinder and Schroeder, 1987) which could be defined as the difference between previous role and new role, role ambiguity (Harvey 1982; Pinder and Schroeder, 1987), role conflict (Kahn et al., 1964), the amount of ambiguity (Thomas, 1998) and role overload (Kahn et al., 1964; Karasek, 1979; Tung, 1981). Interestingly, although the influence of job factors mainly affect the expatriate work adjustment in the foreign assignment, there were also found some spillover effects of job factors on other facets of adjustment (Thomas, 1998). Thus, the proactive measures taken by an organisation to enhance positive job factors (i.e. factors that have the potential to facilitate adjustment) and reduce negative job factors (i.e. factors that are considered to inhibit adjustment) will decrease the expatriate's failure mainly due to enhancing his or her work adjustment (Black, 1990), but partly also due to the positive effect of work adjustment on other facets of adjustment.

When it comes to organisational factors, organisational culture novelty is expected to increase the uncertainty connected to the work environment (Churn, 1982; Mendenhall and Oddou, 1985). Logically then, the greater the difference between the expatriate's original organisational culture compared to the organisational culture to which an expatriate has been assigned, the more difficult the international adjustment for an expatriate would be (Black et al., 1991). The uncertainty arising from the organisational culture novelty could be reduced by social support from co-workers and possibly superiors from the novel environment that would provide an expatriate with information relating to the description of acceptable, less acceptable, or unacceptable behaviours in the new organisational setting (Pinder and Schroeder, 1987). In a similar vein, a parent company can facilitate the adjustment of an expatriate by remaining in contact with an expatriate by various ways, such as by visits to headquarters, or by some form of distant communication, as the amount of contact with a parent company was found to be positively related to some of facets of expatriate adjustment (Black, 1990). 
Another factor falling into organisational factors that organisations should consider is providing an expatriate and possibly also his family or spouse with logistical support such as housing, grocery stores, schools, etc. This recommendation is based on the findings indicating that logistical support has a potential to reduce uncertainty relating to such issues (Copeland and Griggs, 1985; Tung, 1988) and thus have a positive effect on interaction and general adjustment (Torbiorn, 1982). Certain types of logistical support would be then especially determinant of spouse adjustment as inadequate living conditions would likely create uncertainty, especially when the spouse would tend to spend a significant amount of their time engaged in such activities (Harvey, 1985). Such company assistance was found to be positively correlated to an expatriate job satisfaction (Stroh et al., 1994), and limited research also indicates such support to be a notable predictor of a psychological adjustment of a spouse (DeCieari et al., 1991). Obviously then the research indicates that because there are likely to be differences in expatriates' family situations, gender of an expatriate (Caligiuri and Lazarova, 2002), or work situation of a spouse (Harvey, 1997), the organisational support needs to be tailored to fit specific support requirements of each expatriate and family rather than to be applied universally.

\section{CONCLUSION}

This research overview presents numerous benefits international assignments bring to both expatriates as well as organisations. However, it also indicates cross-cultural adjustment of expatriates to be a complex longterm process accompanied by different physical, psychological, and behavioural reactions. Such reactions were found to be a result of increased uncertainty about the accepted behaviour in a novel environment and its effects on an expatriate's psychology. These effects were found to be in the initial stage generally positive; however, the psychological uncertainty was found to gradually lead to the stage of so-called culture shock, which an expatriate can overcome and get to the stage called adjustment and subsequently to the stage of mastery. Although these stages were attempted to be described by various adaptation development models, they have not withstood critical empirical testing and thus are argued to be either inconclusive or suggested to be completely rejected. In order to minimise costs connected with an expatriate's failure to adjust to novel environment, or his low level of effectiveness due to a complete inability to adjust, different methods facilitating expatriates cross-cultural adjustment were proposed. Firstly, these methods concentrated on the selection process consisting of criteria such as expectations and requirements, individual factors, previous foreign work experience, ability to speak foreign language demographic characteristics, and the existence of a spouse or family. Subsequently, various effects of cross-cultural training and its appropriate use on an expatriate and family were discussed. Lastly, factors influencing the expatriate and the spouse after arrival to the novel environment were analysed concentrating specifically on job factors and organisational factors.

The above-described procedures can, however, only serve as a rough outline to cross-cultural management despite being empirically supported by the research done in different countries. It is crucial to understand that this is due to the fact that each country is in some ways different from any other country, and thus unique. Therefore, this uniqueness of an expatriate's home country and novel country which an expatriate is entering would always to some extend affect the expatriate. Based on inductive reasoning it is because of this uniqueness of every country that the theories describing more generally cross-cultural adjustment and its management cannot be taken for certain (unless the theory is specifically derived from and supported by the empirical evidence of the expatriate's home country and the novel country that an expatriate is entering). but can only be considered as probable on the two specific cultures. Similarly, described procedures should be tailored in a way to reflect specific requirements and characteristics of each individual assignment. 


\section{REFERENCES}

Abe, H. and Wiseman, R., L. (1983) 'A Cross Cultural Confirmation of the Dimensions of Intercultural Effectiveness', International Journal of Intercultural Relations, 7, pp. 5-67.

Adler, N.J. (1983) 'Cross-Cultural Management Research: The Ostrich and the Trend', Academy of Management Review, 8(2), pp. 226-232.

Adler, N.J. (1986) International Dimensions of Organizational Behavior. Boston: PSW-Kent.

Anderson, B.A. (2005) 'Expatriate selection: Good management or good luck?', International Journal of Human Resource Management, 16, pp. 56-57.

Armes, K., and Ward, C. (1989) "Cross Cultural Transition and Sojourner Adjustment in Singapore', Journal of Social Psychology, 129(2) pp. 273-275.

Bandura, A. (1997) Social Learning Theory. Englewood Cliffs, NJ: Prentice-Hall.

Befus, C.P. (1988) 'A multilevel treatment approach for culture shock experienced by sojourners', International Journal of Intercultural Relations, 12, pp. 381-400.

Benson, P.G. (1978) 'Measuring cross-cultural adjustment: The problem of criteria', International Journal of Intercultural Relations, 2(1), pp. 21-37.

Bernardo, K. (2006) The U-Curve of Adjustment: A Study in the Evolution and Evaluation of a 50-year old Model. Bedfordshire, UK: Luton Business School.

Berry, J.W., Dasen, P.R. and Saraswathi, T.S. (1997) Handbook of Cross Cultural Psychology, 2nd. edn. USA: Allyn er Bacon.

Black, J.S. (1988) 'Work Role Transitions: A Study of American Expatriate Managers in Japan', Journal of International Business Studies, 19(2), pp. 277-294.

Black, J.S. (1989) 'The Influence of the Spouse on American Expatriate Adjustment and Intent to Stay in Pacific Rim Overseas Assignment', Journal of Management, 15(4), pp. 529-544

Black, J.S. and Gregersen, H.B. (1991) 'The Other Half of the Picture: Antecedents of Spouse Cross-Cultural Adjustment', Journal of International Business Studies, 22(3), pp. 461-477.

Black, J.S., Gregersen, H.B. and Stroh, L.K. (1999) Globalizing People Through International Assignments. Reading, MA: Addison Wesley.

Black, J. S. and Mendenhall, M. (1990) 'Cross-Cultural Training Effectiveness: A Review and a Theoretical Framework for Future Research', Academy of Management Review, 15(1), pp. 113-136.

Black, J. S., Mendenhall, M. and Oddou, G.R. (1991) 'Towards a Comprehensive Model of International Adjustment: An Integration of Multiple Theoretical Perspectives', Academy of Management Review, 15(1), pp. 113-136.

Black, J.S. and Stephens, G.K. (1989) 'The Influence of the Spouse on American Expatriate Adjustment in Overseas Assignment', Journal of Management, 15, pp. 529-544.

Blaikie, N. (1993) Approaches to Social Enquiry. Cambridge: Polity Press.

Borman, W.A. (1968) 'The problem with expatriate personnel and their selection in international enterprises',

Management International Review, 8(4-5), pp. 37-48.

Boyacigiller, N. (1991) International Human Resource Management. Boston: PWS-Kent.

Brack, L.B. (2013) Theory Reflections: Cultural Adaptations, Culture Shock and the "Curves of Adjustment". Available at: http:/ / www.nafsa.org/_/file/_/theory_connections_adjustment.pdf (Accessed: 1 November 2013).

Brein, D. and David K.H. (1971) 'Intercultural communication and the adjustment of the sojourner', Psychological Bulletin, 76, pp. 215-230.

Brett, J. (1980) 'The Effect of Job Transfers on Employees and their Families', in Current Concerns in Occupational Stress. New York: Wiley, pp. 99-136.

Briody, E.K. and Chrisman, J.B. (1991) 'Cultural adaptation on overseas assignments', Human Organization, 50(3), pp. $264-282$.

Brislin, R., MacNab, B. and Nayani, F. (2008) 'Cross-cultural training: Applications and research'. In Smith, P.B., Peterson, M.F. and Thomas D.C. Handbook of cross-cultural management research. pp.397-410. Thousand Oaks, CA: Sage. 
Caligiuri, P. and Lazarova, M. (2002) 'A model for the influence of social interaction and social support on female expatriates' cross-cultural adjustment', International Journal of Human Resource Management, 13, pp. 761-772.

Caligiuri, P., Phillips, J., Lazarova, M., Tarique, I. and Burgi, P. (2001) 'The theory of met expectations applied to expatriate adjustment: The role of cross-cultural training', International journal of Human Resource Management, 12, pp. 357-372.

Churn, A.T. (1982) 'Sojourner Adjustment', Psychological Bulletin, 91(3), pp. 540-572.

Copeland, L. and Griggs, L. (1985) Going International, New York: Random House.

Cui, G. and Van den Berg, S. (1991) 'Testing the Construct Validity of Intercultural Effectiveness', International Journal of Intercultural Relations, 15, pp. 227-241.

Cushner, K. (1994) Training for the global executive. London: Sage Publications.

Dawis, R.V. and Lofquist, L.H. (1984) A Psychological Theory of Work Adjustment. Minneapolis: University of Minnesota Press.

DeCieri, H., Downing, P.J. and Taylor K.F. (1991) 'The psychological impact of expatriate relocation on partners', International Journal of Human Resource Management, 2(3), pp. 337-414.

Desphande, S.P. and Viswesvaran, C. (1992) 'Is cross-cultural training of expatriate managers effective: A meta-analysis', International Journal of Intercultural Relations, 16, pp. 295-310.

Dunbar, E. (1992) 'Adjustment and satisfaction of expatriate U.S. personnel', International Journal of Intercultural Relations, 18, pp. 277-291.

Dunbar, E. and Ehrlich, M. (1986) International Practices, Selection, Training, and Managing International Staff: A Survey Report, Project on International Human Resource. New York: Colombia University, Teachers College.

Eagleton, T. (2000) The idea of culture. Oxford: Blackwell.

Earley, P.C. (1987) 'Intercultural training for managers: A comparison for documentary and interpersonal methods', Academy of Management Journals, 30, pp. 685- 698.

Enderwick, P. and Hodgson, D. (1993) 'Expatriate management practices of New Zealand business', International Journal of Human Resource Management, 4, pp. 407-423.

Eschbach, D.M., Parker, G.E. and Stoeberl, P.A. (2001) 'American repatriate employees' retrospective assessments of the effects of cross-cultural training on their adaptation to international assignments', International Journal of Human Resource Management, 12, pp. 270- 287.

Feldman, D.C. and Bolino, M.C. (1999) 'The impact of on-site mentoring on expatriate socialization: A structural equation modeling approach', International Journal of Human Resource Management, 10, pp. 54-71.

Feldman, D.C. and Thompson, H.B. (1993) 'Expatriation, repatriation and domestic geographical location: an empirical investigation of adjustment to new job assignments', Journal of International Business Studies, 24(2), pp. 507-529.

Fisher, R. (2009) 'Where is Culture in Cross Cultural Research? An Outline of a Multilevel Research Process for Measuring Culture as a Shared Meaning System', International Journal of Cross Cultural Management, 9(1), pp. 25-49.

Friedman, T.L. (2005) The World is Flat: A Brief History of the Twentieth Century. New York: Farrar, Straus, and Giroux.

George, L. (1980) Role transition in later life. Belmont, CA: Wadsworth.

Giddens, A. (1999) Runaway World: How Globalization is Reshaping Our Lives. London: Profile Books.

Graf, A. (2004) 'Expatriate selection: An empirical study identifying significant skill profiles', Thunderbird International Business Review, 46, pp. 667-685.

Grove, C.L. and Torbiorn, I. (1985) 'A new conceptualisation of intercultural adjustment and goals of training', International Journal of Intercultural Relations, 9, pp. 205-233.

Gudykunst, W.B., Hammer, M.R. and Wiseman, R.L. (1977) 'An analysis of an integrated approach to cross cultural training', International Journal of Intercultural Relations, 1, pp. 99-110.

Gullahorn, J.T. and Gullahorn J.E. (1963) 'An extension of the U-curve hypothesis', Journal of Social Issues, 19, pp. 33-47.

Harris, P. (1979) 'The Unhappy World of the Expatriate', International Management, July, pp. 49-50.

Hays, R.D. (1971) 'Ascribed behavioral determinants of success-failure among U.S. expatriate managers', Journal of International Business Studies, 2(1), pp. 40-46. 
Harvey, M.C. (1985) 'The Executive Family: an Overlooked Variable in International Assignments', Columbia Journal of World Business, Spring, pp. 84-92.

Harvey, M.C. (1997) 'Dual career expatriates: Expectations, adjustment and satisfaction with international relocation', Journal of International Business Studies, 28, pp. 627-658.

Harzing, A.W.K. (1995) 'The persistent myth of high expatriate failure rate', The International Journal of Human Resource Management, 6(2), pp. 457-474.

Hays, R.D. (1971) 'Ascribed Behavioral Determinates of Success-failure among U.S. Expatriate Managers', Journal of International Business Studies, 2, pp. 40-46.

Howard, C.G. (1974) 'Model for the design of a selection program for multinational executives', Public Personnel Management, March-April, pp. 138-145.

Inkpen, A. and Ramaswamy, K. (2006) Global Strategy: Creating and Sustaining Advantage across Borders. London: Oxford University Press.

Ivancevich, J.M. (1969) 'Selection of American managers for overseas assignments', Personnel Journal, March, pp. 189-193.

Kahn, R.L., Wolfe, D.M., Quin, R.P. and Snoek, J.D. (1964) Organizational Stress. New York: Waley.

Kanter, R.M. (1991) 'Transcending business boundaries: 12,000 world managers view change', Harvard Business Review, May/June, pp. 151-164

Karasek, R. (1979) 'Job demands, job decision latitude, and mental strain: Implication for job redesign, Administrative Science Quarterly, 2, pp. 215-308.

Katz, J. (1977) 'The Effects of a Systematic Training Program on the Attitudes and Behaviors of White People', International Journal of Intercultural Relations, 1, pp. 77-89.

Kohls, L.R. (1996) Survival Kit for Overseas Living, Maine: Intercultural Press.

Lane, H., Maznewski, M. and Mendehall, M. (2004) 'Globalization: Hercules Meets Budhha.' The Blackwell Handbook of Global Management: a Guide to Managing Complexity. Malden, MA: Blackwell Publishing.

Lee, H.W. (2005) 'The factors influencing expatriates', Journal of American Academy of Business, 6(2), pp. 273-278.

Lefley, H. (1985) 'Impact on Cross-Cultural Training on black and White Mental Health Professionals', International Journal of Intercultural Relations, 9, pp. 305-318.

Louis, M.R. (1980) 'Surprise and Sense Making: What Newcomers Experience in Entering Unfamiliar Organizational Setting', Administrative Science Quarterly, 25, pp. 226-251.

Lysgaard, S. (1995) 'Adjustment in a Foreign Society: Norwegian Fulbright Grantees Visiting United States.' International Social Science Bulletin, 7, pp. 45-51.

McDaniel, C.O., McDaniel, N.C. and McDaniel, A.K. (1988) 'Transferability of Multicultural Education from Training to Practice', International Journal of Intercultural Relations, 12, pp. 19-33.

Meglino, B.M. and DeNisi, A. (1987) 'Realistic job previews: Some thoughts on their more effective use in managing the flow of human resources', Human Resource Planning, 10, pp. 157-167.

Mendenhall, M. and Oddou, G. (1985) 'The dimensions of expatriate acculturation', Academy of Management Review, 10, pp. 39-47.

Miller, E.L. (1975) 'The job satisfaction of expatriate American managers: A function of regional location and previous work experience', Journal of International Business Studies, 6(2), pp. 65-73.

Minkler, M. and Biller, R.P. (1979) 'Role Shock', Human Relations, 32, pp. 125-140.

Mitchell, T., R., Dossett, D., Fiedler, F. and Triandis, H. (1972) 'Cultural training: Validation evidence for the cultural assimilator, International Journal of Psychology, 7, pp. 97-104.

Mol, S.T., Born, M.P., Willemsen, M.E., and Van der Molen, H.T. (2005) 'Predicting expatriate job performance for selection purposes: A quantitative review', Journal of Cross-Cultural Psychology, 33(5), pp. 590-620.

Moran, R.T. (1989) Managing Cross Cultural Differences. Houston, TX: Gulf Publishing.

Morris, M. and Robbie, C. (2001) 'A meta-analysis of the effects of cross-cultural training on expatriate performance and adjustment', International Journal of Training and Development, 5(2), pp. 112-125. 
Naumann, E. (1993) 'Organizational predictors of expatriate job satisfaction', Journal of International Business Studies. 24, pp. 61-80. Nicholson, N. (1984) 'A Theory of Work Role Transition', Administrative Science Quarterly, 29, pp. $172-191$.

Nicholson, N., and Imaizumi, A. (1993) 'The adjustment of Japanese expatriates to living and working in Britain', British Journal of Management, 4, pp. 119-134.

Oberg, K. (1960) 'Cultural Shock: Adjustment to New Cultural Environments', Practical Anthropology, 7, pp. 177-182.

O'Brien, G.E., Fiedler, F.E. and Hewett, T. (1970) The effects of programmed culture training upon the performance of volunteer medical teams', Human Relations, 24, pp. 209-231.

Parker, B. and McEvoy, G.M. (1993) 'Initial examination of a model of intercultural adjustment', International Journal of Intercultural Relations. 17, pp. 355-379.

Piet-Pelon, N.J. and Hornby, B. (1992) Women's Guide to Overseas Living. 2nd edn. Yarmouth: Intercultural Press.

Pinder, C.C. and Schroeder, K.G. (1987) 'Time to proficiency following job transfers', Academy of Management Journal, 30(2), pp. 336-353.

Randolph, G., Landis, D. and Tzeng, O.C. (1977) 'The Effects of Time and Practice upon Culture Assimilator Training', International Journal of Intercultural Relations, 1, pp. 105-119.

Reichers, A.E. (1985) 'A Review and Reconceptualization of Organizational Commitment', Academy of Management Review, 10, pp. 465-476.

Rosenzweig, P.M. (1994) 'A Review and Reconceptualization of Organizational Commitment', Academy of Management Review, 10, pp. 465-476.

Schneider, S.C. and Barsoux, J.L. (2002) Managing Across Cultures, 2nd edn. USA: Prentice Hall.

Selmer, J. (2001) 'Expatriate selection: Back to basics?', International Journal of Human Resource Management, 12, pp. 1219-1233.

Stahl, G.K., Miller, E. and Tung, R. (2002) 'Toward the boundary less career: A closer look at the career concept and the perceived implications for an international assignment', Journal of World Business, 37, pp. 216-227.

Steinkalk, E. and Taft, R. (1979) 'The effects of a planed cultural experience on the attitudes and behaviors of the participants', International Journal of Human Relations, 3, pp. 187-197.

Stening, G.W. (1979) 'Problems of Cross-Cultural Contact: A Literature Review', International Journal of Intercultural Relations, 3, pp. 269-313.

Stroh, L.K., Dennis, L.E. and Cramer T.C. (1994) 'Predictors of expatriate adjustment', International Journal of Organisational Analysis, 2, pp. 176-192.

Takeuchi, R. and Hannon, J.M. (1996) The antecedents of adjustment for Japanese expatriates in the United States. Banff, Canada: The Academy of International Business.

Torbiorn, I. (1982) Living Abroad. New York: Wiley.

Tharenou, P. (2003) 'The initial development of receptivity to working abroad: Self-initiated international work opportunities in young graduate employees', Journal of Occupational and Organisational Psychology, 76, pp. 489-508.

Thomas, D.C. and Fitzsimmons, S.R. (2008) 'Cross-cultural skills and abilities: From communication competence to cultural intelligence', in Smith, P.B., Peterson, M.F. and Thomas D.C. (eds.) Handbook of cross-cultural management research 9. Thousand Oaks, CA: Sage, pp. 201-218.

Thomas, D.C. and Lazarova, M.B. (2006) 'Expatriate adjustment and performance: A critical review', in Stahl, G.H. and Bjorkman, I. (eds.) Handbook of research in international human resource management. Cheltenham, UK: Edward Elgar, pp. 247-264.

Thomas, D.C. (1998) 'The expatriate experience: A critical review and synthesis', Advances in International Comparative Management, 12, pp. 237-273.

Tung, R.L. (1981) 'Selection and training of personnel for overseas assignments', Columbia Journal of World business, 16, pp. 68-78.

Tung, R.L. (1981) 'Selecting and Training Procedures of U.S., European, and Japanese Multinational Corporations', California Management Review, 25, pp. 57-81.

Tye, M.G. and Chen, P.Y. (2005) 'Selection of expatriates: Decision making models used by HR professionals', Human Resource Planning, 28(4), pp. 15-20. 
Wanous, J.P. and Lawler, E.E. (1972) 'Measurement and Meaning in Job Satisfaction', Journal of Applied Psychology, 56, pp. 95-105.

Ward, C., Bochner, S. and Furnham, A. (2001) The Psychology of Culture Shock. 2nd edn. Philadelphia, PA: Routledge. Worchel, S. and Mitchell, T.R. (1972) 'An evaluation of the effectiveness of the culture assimilator in Thailand and Greece', Journal of Applied Psychology, 56, pp. 472-479.

Xia, J. (2009) 'Analysis of Impact of Culture Shock on Individual Psychology', International Journal of Psychological Studies, 1(2), pp. 97-101. 